\title{
Estabilidade no Serviço Público: um estudo de caso aa Autarquia Educacional do Vale do São Francisco
}

\author{
Ícaro Teixeira Amorim ${ }^{1}$; Ricardo Alves de Oliveira ${ }^{2}$; Maria do Socorro Macêdo Coelho Lima ${ }^{3}$
}

\begin{abstract}
Resumo: Este artigo pretende avaliar a importância da estabilidade para os servidores da Autarquia Educacional do Vale do São Francisco - AEVSF, Mantenedora da Faculdade de ciências Aplicadas e Sociais da Petrolina - FACAPE. Buscou-se com o resultado desta averiguação saber qual o ganho trazido para o servidor e para a sociedade. O estudo também tem o intuito de descrever a estabilidade do servidor público nos seus diversos conceitos, tanto doutrinário como legal. A metodologia utilizada neste trabalho foi de cunho descritivo, baseada em estudo de caso, onde foram entrevistados os servidores efetivos da FACAPE.
\end{abstract}

Palavras-Chave: Estabilidade. Servidor Público. Sociedade.

\section{The Stability of the Institute in Public Service: a Case Study of the Autarquia Educacional do Vale do São Francisco}

\begin{abstract}
This article aims to evaluate the importance of stability for Autarquia Educacional do Vale do São Francisco - AEVSF, Maintainer of the Faculdade de ciências Aplicadas e Sociais da Petrolina - FACAPE. He attempted with the outcome of this investigation to know what the gain brought to the server and to society. The study also aims to describe the stability of public servants in their various concepts, both doctrinal and legal. The methodology used was a descriptive nature, based on case study where respondents were the actual servers FACAPE.
\end{abstract}

Keywords: Stability. Civil Servants. Society

\section{Introdução}

Desde a primeira Constituição Federal, outorgada em 1824, observa-se ensaios sobre da estabilidade do servidor público. Com o passar dos anos, as leis no Brasil sofreram mudanças para melhor regulamentar os direitos e deveres dos servidores públicos, contudo, somente na Constituição de 1934, foi previsto o instituto da estabilidade, ainda que o termo “estável" não fosse usado explicitamente.

\footnotetext{
${ }^{1}$ Pós-graduando em gestão pública - Univasf/UAB. End. Eletrônico: icaro.amorim@live.com

${ }^{2}$ Pós-graduado em gestão pública municipal - Univasf/UAB. End. Eletrônico: ricardo.alves@ facape.br

${ }^{3}$ Professora orientadora. Mestre em economia. End. Eletrônico: socorrofacape@ hotmail.com
} 
Essa pesquisa vem ao encontro deste tema fazendo uma abordagem dos conceitos de estabilidade tanto doutrinário como legal. Sua pesquisa de campo está delimitada ao estudo da estabilidade do servidor público da Autarquia Educacional do Vale do São Francisco AEVSF.

Este trabalho está estruturado em quatro capítulos. O primeiro capítulo inicia-se com a introdução.

O segundo capítulo são os procedimentos metodológicos, isto é, a metodologia utilizada, dos objetivos e da justificativa para o desenvolvimento deste.

O terceiro capítulo faz uma abordagem sobre a visão geral do conceito e da origem da estabilidade do servidor público, tratando da evolução legal da estabilidade do servidor público, além de descrever uma breve abordagem da estabilidade do ponto de vista geral.

E por fim, o quarto capítulo aborda a apresentação e análise das informações obtidas na pesquisa. Este capítulo dá ênfase à origem das informações utilizadas na pesquisa, bem como mostra o resultado do trabalho através da análise descritivas dos dados.

\section{Metodologia}

Esta pesquisa tem cunho descritivo e utiliza como meio um estudo de caso. As fontes dessas informações basearam-se em livros que tratam a respeito da estabilidade do servidor público, revistas, artigos eletrônicos, monografias e questionário aplicado aos servidores da Autarquia Educacional do Vale do São Francisco.

O principal objetivo deste trabalho configura-se investigar a evolução legal do processo da estabilidade para o servidor público, avaliar o impacto do instituto da estabilidade nos servidores da Autarquia Educacional do Vale do São Francisco - AEVSF na prestação de serviço público educacional na sua mantida, a Faculdade de Ciências Aplicadas e Sociais de Petrolina - FACAPE, os efeitos da estabilidade no comportamento dos servidores da AEVSF como também no desempenho de suas funções dentro da Instituição.

A justificativa para o desenvolvimento desta pesquisa se configura na busca pelo conhecimento, além de contribuir com informações para os servidores públicos da Autarquia 
Id on Line Revista Multidisciplinar e de Psicoloqia

Id on Line Multidisciplinary Journal and Psycology

e a sociedade em geral, servindo este estudo também como fonte de pesquisa para outros trabalhos referentes ao assunto.

\section{O Conceito de Estabilidade no Serviço Público}

O conceito de estabilidade ora tratado neste estudo, advém de duas bases: do ponto de vista doutrinário e do ponto de vista legal. Do ponto de vista doutrinário, a estabilidade no serviço público possui vários conceitos que determinam o seu real significado.

Segundo Diniz (2004 apud GUIMARÃES FILHO, p.11) conceitua estabilidade no serviço público como "um atributo do cargo público que assegura a continuidade da prestação do serviço público, que é de caráter permanente". É também uma espécie de ligação entre a pessoa estatal e o servidor público. Enquanto que Rocha (2001 apud GUIMARÃES FILHO, p.11), diz que:

A estabilidade é um atributo da efetividade e deriva do cumprimento de certas condições (decorre da aplicação de certos princípios, dentre eles o da legalidade, da isonomia e da eficiência) tais como de concurso público e aprovação em estágio probatório.

Ainda abordando esta doutrina:

A estabilidade não concerne ao cargo, nem mesmo ao servidor, conquanto afete diretamente a relação jurídica por ele firmada, bem como o regime jurídico que irá informá-la, incidindo, ainda, sobre o cabedal de bens jurídicos que formam o seu patrimônio (ROCHA, 1999, p.249).

É relevante ressaltar que dentre os conceitos doutrinários de estabilidade, não se pode confundi-la com efetividade. Meirelles (2001, p.45) enfoca "estabilidade como um atributo pessoal do servidor, enquanto que a efetividade é uma característica do provimento de certos cargos". Para Brandão Cavalcanti (1936, p.572) "a estabilidade consiste na indemissibilidade, independente de processo criminal ou administrativo, com todos os elementos de defesa".

Para Guimarães Filho (2004, p.10) ressalta em seu trabalho que a estabilidade surgiu nos Estados Unidos da América, visando evitar algumas práticas antidemocrática e predatória na Administração Pública. Isso se deu em decorrência da constante alternância de partidos políticos (Democratas e Republicanos) no poder público daquele país. 
Id on Line Revista Multidisciplinar e de Psicologia

Id on Line Multidisciplinary Journal and Psycology

A estabilidade veio para abolir o que podia se chamar de "quem manda é quem está no poder", a Constituição Federal de 1934 foi quem abordou de fato a questão da estabilidade para o servidor público, e daí com a vinda das demais constituições o termo "estabilidade" foi apenas sendo aperfeiçoado.

\section{Processo Evolutivo da Estabilidade}

Ao abordar o processo evolutivo da estabilidade, principalmente no âmbito constitucional, é necessário se falar de todas as Constituições Brasileiras, descrevendo-as desde o surgimento, a evolução até os dias atuais, bem como, falar das leis que operam em consonância com a Constituição em vigor.

A Constituição Federal de 25 de março de 1824, onde determinava que todo cidadão brasileiro poderia ser admitido aos cargos públicos, civis, políticos ou militares como servidor público, possuindo apenas como pré-requisitos, os talentos e as virtudes individuais. De acordo com o que rezava esta Constituição, não era necessário a prestação de concurso para a investidura no cargo público (BRASIL, 1824).

Assim, a Constituição seguinte que foi outorgada em 1891, trouxe um avanço no seu texto constitucional em relação ao texto da Constituição anterior, porém não fazia menção no instituto da estabilidade no serviço público, o que mais uma vez não se explicitava a estabilidade para os servidores públicos federais. O artigo 73 da referida Constituição dizia que, "os cargos públicos civis, ou militares, são acessíveis a todos os brasileiros, observadas as condições de capacidade especial, que a lei estatuir, sendo, porém, vedadas as acumulações remuneradas".

É importante ressaltar que a Constituição de 1891 já previa a garantia de aposentadoria para os funcionários públicos, mas, com a ressalva de que só poderiam adquiri-la por invalidez a serviço da nação.

Com isso, a Constituição de 1934 tornou-se a primeira Carta brasileira a mencionar o instituto da estabilidade em um de seus artigos, só que de forma não direta, pois, não utilizava a expressão "estável". O artigo 169 desta Constituição dizia que a estabilidade chegaria aos funcionários públicos, depois de 02 (dois) anos, quando nomeados em virtude de concurso de provas, ou então, depois de 10 (dez) anos de efetivo exercício. 
Um ponto interessante a ser notado neste artigo é referente àqueles servidores que exerciam cargo público sem que tivessem prestado concurso público conforme previa o referido artigo. A questão a ser discutida é que após 10 (dez) anos de efetivo exercício estes servidores não mais poderiam ser demitidos, passando assim a alcançar a estabilidade. Nesse caso é o que se pode chamar de direito adquirido. E esse direito perdurou até que se aposentassem.

A Constituição de 1934 trouxe benefício no tocante ao instituto da estabilidade do servidor público na administração pública. Ela dizia que os funcionários públicos só poderiam perder seus cargos em razão de sentença judiciária ou mediante processo administrativo, assegurando-lhes sempre o direito à defesa, o que antes não era previsto nas Constituições anteriores. Fernandes (apud DANTAS 2000), analisou a estabilidade do servidor público na Carta de 1934, como sendo "uma conquista democrática, porque o titular do cargo conquistado pelo mérito não estaria sujeito às injunções políticas, podendo representar o interesse público mesmo contra a vontade de dirigentes".

A Constituição Federal de 1937, não trouxe mudanças no instituto da estabilidade, manteve os mesmos direitos para os servidores públicos aludidos na Carta de 34.

A outorga da Carta Constitucional de 1946, trouxe mudanças na essência da estabilidade. No seu artigo 186, determinava que a exigência do concurso público permaneceria precedida da inspeção de saúde, para a primeira investidura em cargos de carreira e em outros que a lei determinasse. Mas, a mudança propriamente dita, foi aludida no artigo 188, onde o mesmo trazia o termo “estáveis". Referente à Constituição de 1967, essa não trouxe mudanças para o instituto da estabilidade do servidor público. Permaneceu quase que inalterado em relação à Constituição de 1946.

No mais, a Constituição que veio dar mais clareza ao instituto da estabilidade, foi a Constituição Federal de 1988. Essa Constituição ficou conhecida como Carta Cidadã, pois, sua criação teve participação popular, conforme evidencia Gomes (apud DANTAS 2000) que “esse objetivo foi alcançado não só pela intensa e até então, inédita no país, participação do cidadão no processo de elaboração da Constituição, mas pela incorporação em seu texto de mecanismos dessa participação da coisa pública”.

O artigo 41 da referida Constituição tratava os servidores públicos como estáveis após 02 (dois) anos de efetivo exercício, nomeados em virtude da prestação de concurso público. 
Id on Line Revista Multidisciplinar e de Psicoloqia

Id on Line Multidisciplinary Journal and Psycology

Porém, houve uma mudança no texto constitucional, no que diz respeito ao fator tempo. A Emenda Constitucional no 19/98, alterou o artigo 41 da CF/88 de 02 (dois) para 03 (três) anos o tempo de serviço prestado para aquisição da estabilidade.

A Lei do município de Petrolina-Pe, nº 301/91, conhecida como Estatuto do Servidor Público de Petrolina, traz em seu artigo 22 a legalidade da estabilidade do servidor público de Petrolina, adotando os mesmos critérios citados no artigo 41 da CF/88, só que com a criação da referida Emenda Constitucional, o artigo em questão também foi alterado automaticamente.

\section{Finalidade do Instituto da Estabilidade}

A finalidade do instituto da estabilidade é o que muitos estudiosos interpretam como sendo a maneira do Estado Brasileiro possibilitar a toda sociedade a continuidade dos serviços públicos, daí a permanência de servidores qualificados e treinados em seus quadros.

O intuito do Estado é de que o servidor tenha consciência de que está garantido no seu emprego e em troca disso preste no mínimo um serviço de qualidade à população em geral que necessita dos serviços.

Um ponto interessante a ser discutido aqui, já que está se falando em finalidade do instituto da estabilidade, é a questão da garantia do emprego ao servidor público.

A estabilidade traz sim a garantia no exercício das funções do servidor, porém, ressalva-se que o mesmo não poderá infringir os seus deveres como servidor público da Autarquia Educacional do Vale do Francisco previstos na Lei municipal de Petrolina-PE n $^{\circ}$ 301/1991. Daí, de acordo com a gravidade da infração, ele poderá ser afastado do exercício após julgamento. Não resta dúvida de que a estabilidade é a garantia fundamental para o bom desempenho dos serviços públicos.

Para que a estabilidade torne-se evidente, é necessário que o servidor público passe primeiro por um período de avaliação de função, período este chamado de estágio probatório.

\section{Estágio Probatório}

O estágio probatório e a estabilidade são institutos totalmente diferentes. O estágio probatório é o principal requisito para a aquisição da estabilidade, enquanto que a estabilidade 
Id on Line Revista Multidisciplinar e de Psicoloqia

Id on Line Multidisciplinary Journal and Psycology

é um direito adquirido pelo servidor público constante na Constituição Federal/88 e nas leis e estatutos que agem em consonância com a referida Constituição.

Existem algumas definições a respeito de estágio probatório. Fontes (1996) conceitua estágio probatório, como sendo:

O lapso de tempo, que se inicia com o efetivo exercício do servidor nomeado por concurso público, no qual será submetido à verificação de sua capacidade para o exercício do cargo, da compatibilidade de sua conduta com a disciplina do serviço público.

Segundo Queiroz (2005, p.1) que "trata o estágio probatório como uma avaliação que o servidor de cargo efetivo se submete para verificar se ele merece ou não se estabilizar no serviço público". Normalmente, ele é avaliado quanto a sua assiduidade, pontualidade, responsabilidade, iniciativa para exercer as atribuições do cargo, entre outras. Essa previsão está evidenciada no artigo 23 da Lei municipal de Petrolina-PE nº 301/91.

É de suma importância salientar que o servidor público que não passar no estágio probatório será exonerado do cargo automaticamente. Ressalta-se que durante o estágio probatório, o servidor passará por 06 (seis) avaliações, uma a cada semestre.

O artigo 76 da Lei municipal de Petrolina-PE n 301/91 diz que, o servidor estável só perderá o cargo através de sentença judicial transitada em julgado ou através de processo administrativo disciplinar. Então daí, cabe salientar que apesar da estabilidade, o servidor público da AEVFS não está totalmente garantido no exercício do dever, apenas é mais dificultoso o servidor público ser demitido do que um servidor da iniciativa privada.

\section{Regras para aquisição da estabilidade}

Para que um servidor público consiga alcançar a sua estabilidade no serviço público, se faz necessário seguir duas regras legais, impostas pela $\mathrm{CF} / 88$. Vale ressaltar que essas regras não são amplas, mas são de grande importância para o servidor que está buscando a sua estabilidade. As regras são as seguintes: a) Caráter temporal, 03 (três) anos no estágio probatório, conforme Emenda Constitucional 19/98; b) Obrigatoriedade de passar por uma avaliação especial de desempenho por comissão constituída para a finalidade da estabilidade.

Denota-se que as regras supracitadas, tornam-se um fator de seleção, e que, portanto, provoca medo ao servidor público. Então, vale frisar que a estabilidade não é adquirida com 
Id on Line Revista Multidisciplinar e de Psicologia

Id on Line Multidisciplinary Journal and Psycology

uma simples aprovação nos concursos públicos. Para se tê-la, o candidato aprovado passa por todo um processo de avaliação, visando a qualidade profissional para se tornar um bom servidor público.

\section{A estabilidade e a prestação do serviço público.}

Observa-se que no nosso ordenamento jurídico, aparecem aberturas ou brechas que impossibilitam a aplicação das regras para o preenchimento dos cargos públicos através de concursos. As nossas legislações anteriores permitiam a nomeação de servidores públicos sem que prestassem concurso público e no decorrer do tempo, ao chegarem a 10 (dez) anos de prestação de serviço, esses alcançariam a estabilidade.

Considera-se este ponto como grave, pois, eram servidores que não passavam pelo processo do estágio probatório, ou seja, não passavam por avaliação de desempenho da sua capacidade profissional. Eram os chamados cargos de confiança. Essas nomeações de servidores públicos sem qualquer prestação de concurso público levavam a crer que por trás disso restava nada mais do que interesse político. E hoje, esses servidores, já com suas estabilidades alcançadas, continuam em pleno gozo de suas atividades no serviço público até que se aposentem.

Fontes (1996, p. 42) vem reforçar a tese descrita acima:

E não se deve deixar de ressaltar que se considerando o universo atual dos servidores estáveis na Administração Pública Brasileira, o percentual daqueles que obtiverem o benefício em decorrência de leis generosas é consideravelmente maior do que o daqueles que nela ingressaram pela porta estreita do concurso público.

Diante disso, quem recebia a grande perda era a sociedade que necessitava dos serviços públicos para desenvolverem suas atividades. Atualmente, ainda não é difícil de notar a má qualidade do serviço público. Sem generalizar, ainda existem vários órgãos públicos que deixam a desejar na prestação do serviço, mas a ocorrência desse fato se dá por causa de gestores públicos que enchem a máquina estatal através de nomeação de servidores, onde se pode até pensar que tudo isso não passa de troca de favores.

Trazendo a estabilidade versus prestação do serviço público para uma visão mais holística, nota-se que a estabilidade não é o fator preponderante para a deficiência e inoperância das atividades públicas. Ao contrário disso, ela permite habilitar a qualificação 
funcional de forma crescente, o que torna o serviço público mais especializado. Para tanto, o objetivo da estabilidade na Administração Pública, é assegurar a eficiência do serviço público para a sociedade, pois, pensar de forma contrária, tiraria o sentido da existência do Estado.

\section{Resultados e Discussão}

A pesquisa foi desenvolvida com questionários conforme o anexo I e distribuído por vários setores de trabalho da AEVSF. Foram entrevistados 54 servidores de provimentos efetivos, que responderam 15 perguntas com respostas possíveis entre os dias 09 a 13 de fevereiro de 2015 , destes $72 \%$ é do sexo masculino e $28 \%$ do sexo feminino, sendo $50 \%$ dos servidores com idade entre 18 e 35 anos, $46 \%$ dos servidores com idade de entre 36 a 50 e $4 \%$ dos servidores com mais de 50 anos. Dos servidores entrevistados, $19 \%$ tem menos de 5 anos no serviço público, $13 \%$ tem mais de 5 anos e menos de 10 anos no serviço público, $55 \%$ tem mais de 10 anos e menos de 20 anos no serviço público e $13 \%$ tem mais de 20 anos no serviço público, o percentual de servidores efetivos entrevistados é representado no gráfico abaixo.

Figura 1: Percentual de estabilidade entre os servidores entrevistados.

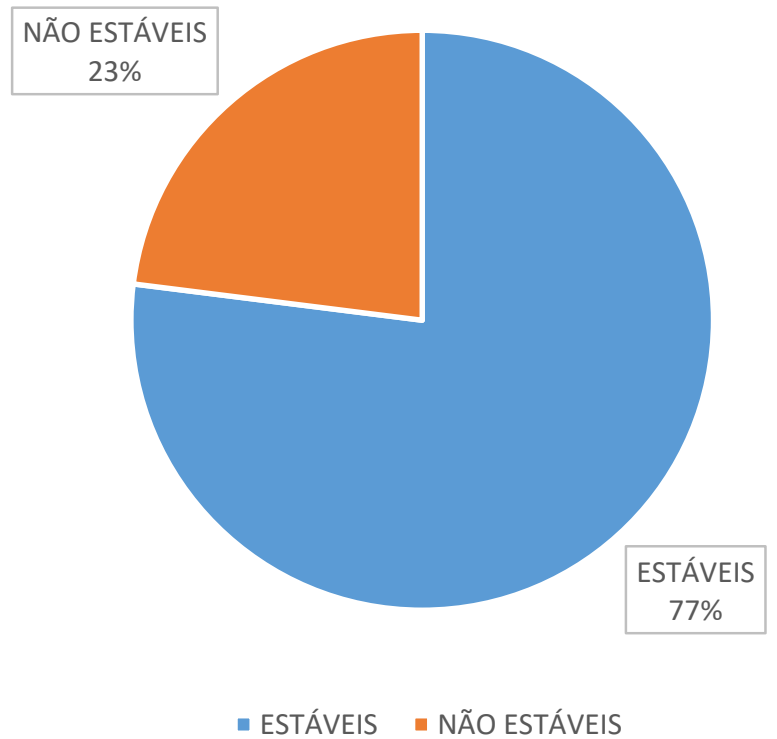

Fonte: Dados da pesquisa 
A entrevista mostra que $65 \%$ dos entrevistados afirmam ter boas condições de trabalho; $80 \%$ dos entrevistados afirmam que sente-se seguros contra as arbitrariedades do seu chefe; $53 \%$ dos entrevistados afirmam que os regulamentos e políticas educacionais da AEVSF/FACAPE são isonômicas; $60 \%$ dos entrevistados não estão satisfeitos com suas remunerações; $55 \%$ dos entrevistados afirmam ter autonomia no trabalho; $77 \%$ dos entrevistados são estáveis no serviço público; 95\% dos entrevistados afirmam que a estabilidade no serviço público dá mais confiança para exigir seus direitos; $100 \%$ dos entrevistados acreditam que as leis que regulamentam a estabilidade são importantes para assegurar o direito dos servidores públicos; $83 \%$ dos entrevistados afirmam conhecer as leis que tratam de estabilidade no serviço público; 95\% dos entrevistados acreditam que o período de estágio probatório é importante para verificar se os funcionários tem aptidão para o cargo que passaram através de concurso público, o Anexo II mostra a tabulação dos dados.

Figura 2: Percepção do servidor estável em relação às possíveis arbitrariedades.

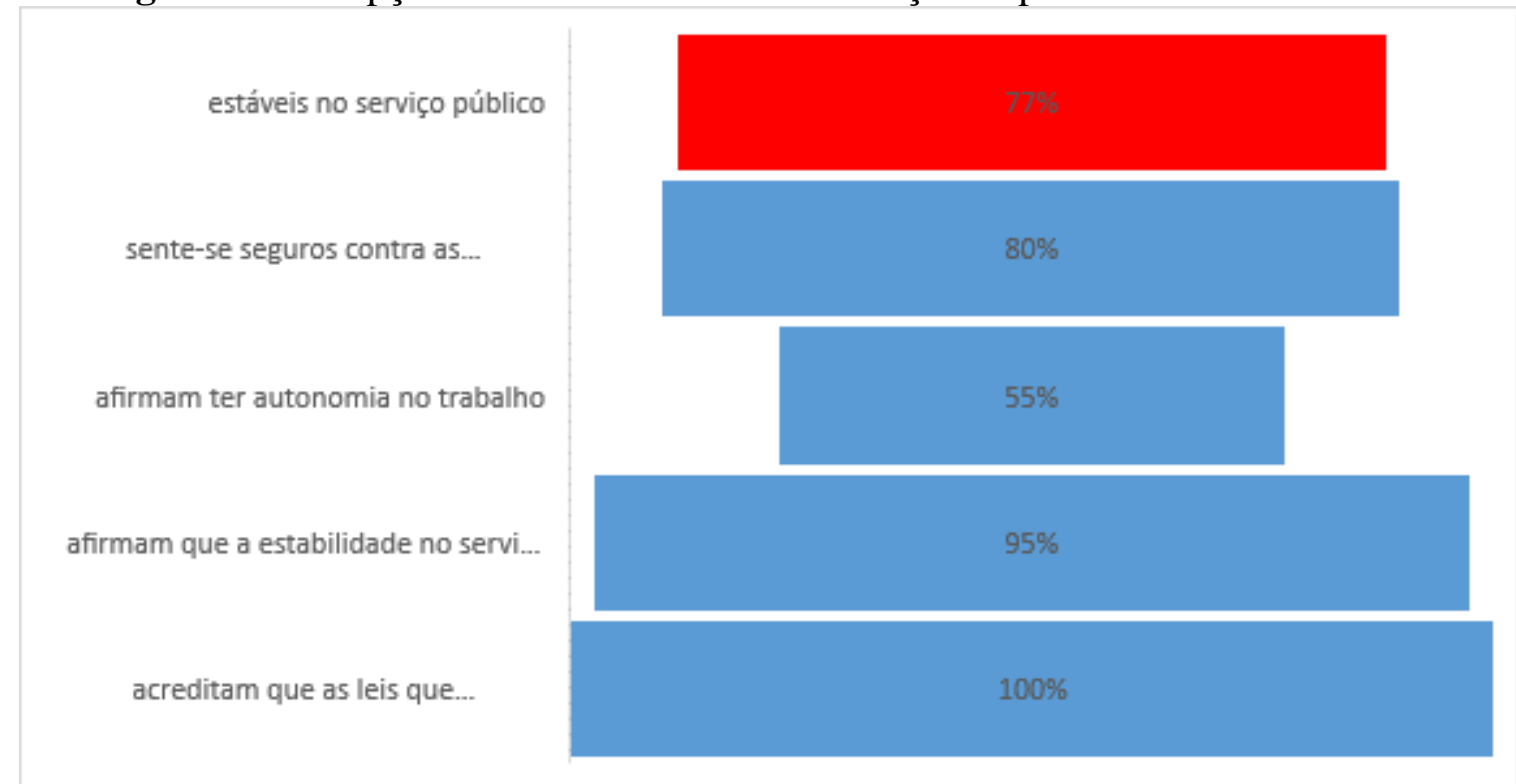

Fonte: Dados da pesquisa

\section{Conclusão}

Previsto nas Constituições de 1934, 1937, 1946, 1967 e com ênfase na atual Constituição Federal de 1988, a qual ficou conhecida como Carta Cidadã, a estabilidade no 
Id on Line Revista Multidisciplinar e de Psicoloqia

Id on Line Multidisciplinary Journal and Psycology

serviço público compreende um atributo que assegura a continuidade da prestação dos serviços públicos.

Desse modo, para que o servidor adquira a estabilidade é necessário ser a aprovado no estágio probatório de três anos e passar por uma avaliação especial de desempenho por uma comissão designada para esse fim.

Os servidores públicos com o passar dos anos estão cada vez mais protegidos por legislações que garantem sua permanência no serviço público. Então diante do estudo realizado, através do questionário aplicado aos servidores públicos da Autarquia Educacional do Vale do São Francisco, pode-se concluir que a maioria dos entrevistados relatam boas condições de trabalho, sentem-se seguros em relação a possíveis arbitrariedade de seus superiores e que são tratados com isonomia, além de terem autonomia em suas funções.

Em relação ao instituto da estabilidade, percebe-se que a maioria dos entrevistados são estáveis no serviço público, afirmam que a estabilidade garante mais confiança para exigir seus direitos e que as leis que regulamentam a estabilidade são relevantes para assegurar esse direito e, sem sombra de dúvida, importante para os servidores efetivos da Autarquia Educacional do Vale do São Francisco - AEVSF.

Conclui-se que foi e é importante a evolução do instituto da estabilidade a fim de coibir as arbitrariedades da autoridade pública sobre o servidor público no exercício de suas funções. Na AEVSF a norma funciona como foi pensada, isto se observa nas respostas do questionário, onde a ampla maioria dos servidores usufruem do instituto da estabilidade. $\mathrm{O}$ servidor sente-se seguro contra arbitrariedades dos superiores e não se acanha ao falar, com isenção, de condições de trabalho, remuneração, hierarquia e autonomia, questões sensíveis na iniciativa privada.

\section{Referências}

CAVALCANTI, Themístocles Brandão. Instituições de Direito Administrativo Brasileiro. RJ/SP: Livraria Editora Freitas Bastos, 1936.

BRASIL. Constituição (1946). Constituição da República Federativa do Brasil. Senado, 1946.

BRASIL. Constituição (1967). Constituição da República Federativa do Brasil. Brasília, DF: Senado, 1967. 
Id on Line Revista Multidisciplinar e de Psicoloqia

Id on Line Multidisciplinary Journal and Psycology

BRASIL. Constituição (1988). Constituição da República Federativa do Brasil. Brasília, DF: Senado, 1988.

BRASIL. Lei 8.112 de 11 de dezembro de 1990. Dispõe sobre o Regimento Jurídico dos Servidores Públicos Civis da União, das Autarquias e das Fundações Públicas Federais. Pub. DOFC 12/10/1990, p. 23935. Diário Oficial da União, Seção I.

BRASIL. Emenda Constitucional nº 19/98. Brasília, DF. Diário Oficial da União de 05.06.98.

BRASIL. Constituição dos Estados Unidos do Brasil (de 18 de setembro de 1946). Disponível em: 〈http://www.planalto.gov.br/ccivil_03/constituicao/constitui\%C3\%A7ao46.htm>. Acesso em: 8 nov. $2014,16: 15$.

BRASIL. Constituição Política do Império do Brasil (de 25 de Março de 1824). Disponível em: <http://www.planalto.gov.br/ccivil_03/constituicao/constitui\%C3\%A7ao24.htm>. Acesso em: 16 nov. 2014, 18:19.

DANTAS, Dagmar Albertina Gemelli. Abordagem sobre a Estabilidade do Servidor Público e a Emenda Constitucional $n^{\circ}$ 19/98. 2000. Artigo.

FONTES, Ana Lúcia Berbert de Castro. Estágio Probatório. Distorção Prática de um Instituto. (Tese aprovada no XXII Congresso Nacional de Procuradores do Estado de Minas, 1996). Revista da Procuradoria Geral do Estado da Bahia - RPGE. Salvador. v.22, Jan./Dez., 1996.

JOÃO, Rodrigues Guimarães Filho. A Estabilidade de servidor público concorre para a manutenção do interesse público e eficiência na Administração Pública. Brasília, 2004. p. 11. Monografia.

MEIRELLES, Hely Lopes. Direito Administrativo. 26.ed. São Paulo: Malheiros, 2001.

ROCHA, Carmem Lúcia Antunes. Princípios Constitucionais dos Servidores Públicos. São Paulo: Saraiva, 1999.

PETROLINA-PE. Lei municipal No 301 de 04 de Junho de 1991. Estatuto dos Funcionários Públicos de Petrolina.

\section{Como citar este artigo (Formato ABNT):}

AMORIM, I.T.; OLIVEIRA, R.A.; LIMA, M.S.A.C. O Instututo da Estabilidade no Serviço Público: um estudo de caso da Autarquia Educacional do Vale do São Francisco. Id on Line Revista Multidisciplinar e de Psicologia, Set-Out de 2016, vol.10, n.31, Supl 2, p. 42-53 ISSN 1981-1179. 